\title{
Trans-Hepatic Percutaneous Endoscopic Gastrostomy Tube Placement: A Case Report of A Rare Complication and Literature Review
}

\author{
Anuj Chhaparia ${ }^{\text {a, d }}$, Muhammad Bader Hammami ${ }^{\mathrm{a}, \mathrm{b}, \mathrm{d}, \mathrm{e}}$, Juri Bassuner ${ }^{\mathrm{c}}$, \\ Christine Hachem ${ }^{\mathrm{a}, \mathrm{b}}$
}

\begin{abstract}
Percutaneous endoscopic gastrostomy (PEG) tubes have emerged as the standard of care for long-term enteral feeding. This procedure is relatively safe; however, complications do occur, and one of the most dreaded complications is trauma to the surrounding organs. Hepatic injury during PEG placement is an extremely rare complication of the PEG procedure, with a handful of cases described in the medical literature. We describe the case of an accidental trans-hepatic placement of a PEG tube in a 78-year-old morbidly obese female, even with excellent trans-illumination and manual external pressure achieved during endoscopic placement. Post-procedure, cross-sectional imaging of the abdomen showed a gastrostomy tube traversing the lateral margin of the liver with adjacent small hematoma. Physical exam was unremarkable for abdominal tenderness or guarding/rigidity, and no blood or drainage was noted at the site of PEG insertion. Enteral nutrition was started after $24 \mathrm{~h}$ of PEG tube insertion and patient tolerated well with no complications. The patient was discharged to a nursing home but unfortunately died the following week to an unknown cause.
\end{abstract}

Keywords: Trans-hepatic PEG; Enteral feeding; Complications; Hepatic injury

\section{Introduction}

Percutaneous endoscopic gastrostomy (PEG) tubes have emerged as the modality of choice for long-term enteral nutri-

Manuscript submitted January 13, 2018, accepted February 5, 2018

aDepartment of Internal Medicine, Saint Louis University School of Medicine, St. Louis, MO, USA

${ }^{b}$ Division of Gastroenterology and Hepatology, Saint Louis University School of Medicine, St. Louis, MO, USA

'Department of Radiology, Saint Louis University School of Medicine, St. Louis, MO, USA

${ }^{\mathrm{d}}$ These authors contributed equally to this article.

${ }^{e}$ Corresponding Author: Muhammad Bader Hammami, Division of Gastroenterology and Hepatology, Saint Louis University School of Medicine, 1402 S. Grand Blvd., St Louis, MO 63104, USA. Email: mbhammami@hotmail.com

doi: https://doi.org/10.14740/gr966w tion in patients with functional bowel who are unable to maintain adequate oral nutrition. Gaudier et al first performed the PEG tube procedure in 1980 and promoted it as a relatively easy and safe alternative to laparotomy [1]. Since then, the popularity of the PEG tube has grown exponentially all over the world, with approximately $200,000-250,000$ procedures being performed in the USA alone [2]. PEG tube placement is now the second most common indication to perform endoscopy of the upper gastrointestinal tract [3].

Enteral nutrition has many inherent advantages over parenteral nutrition. These include maintaining gut function and gut integrity, and decreased risk of hyperglycemia, hypertriglyceridemia, immune dysfunction and infections [4]. PEG tube placement is a very efficient method of enteral feeding, and the procedural success rate of PEG insertion is more than $95 \%$ [5]. Even more, PEG is more comfortable to patients, with decreased risk of aspiration pneumonia, nasal trauma, tube dislodgement and provides longer-term access when compared to nasogastric tube [6].

However, PEG tubes are not completely free of complications. Fortunately, the bulk of the complications associated with PEG tube placement are minor and include wound infection, tube dislodgement or blockage, hernia or fistula formation, ulceration and granuloma formation [7]. Rare but more serious complications of PEG tubes are endoscopy related complications, bleeding, injury to internal organs, buried bumper syndrome, necrotizing fasciitis, tumor seeding and volvulus [7]. Injuries to internal organs are extraordinarily infrequent and represent the most dreaded complication of PEG tube placement. These have been described as isolated case reports in the medical literature and involve injury to the small intestine [8], colon $[9,10]$, mesentery $[11]$ and liver.

Here we describe an unfortunate case of an accidental passage of a PEG tube through the left hepatic lobe parenchyma, followed by a literature review.

\section{Case Report}

A 78-year-old female with past medical history significant for type 2 diabetes mellitus, hypertension, and obesity with (body mass index, BMI of $34 \mathrm{~kg} / \mathrm{m}^{2}$ ) was admitted to our tertiary care hospital following an acute stroke, which resulted in dysarthria and left-sided hemiparesis. Computed tomography of the head 


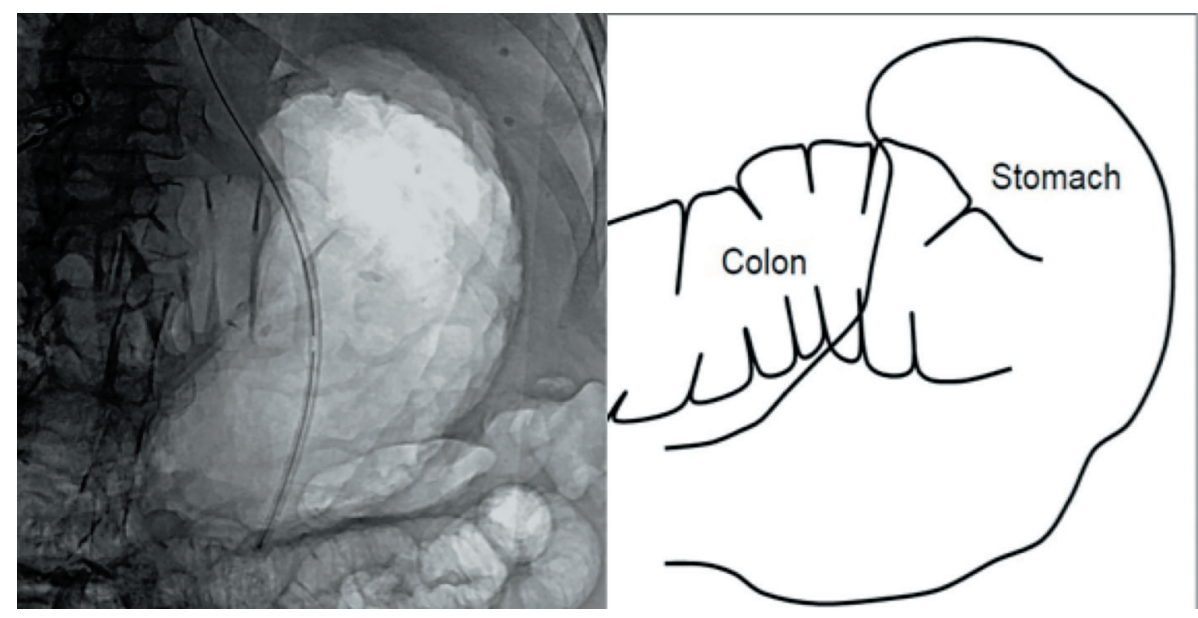

Figure 1. Fluoroscopic evaluation of the abdomen demonstrated an air distended colonic loop anterior to the stomach. Accompanying schematic.

ruled out intracranial hemorrhage, and magnetic resonance imaging of the brain showed an acute infarct in the right genu of the corpus callosum. The patient was started on dual antiplatelet treatment (aspirin and clopidogrel), as per the recommendations from the stroke neurology team. Her hospital course was prolonged with multiple complications, including a code blue for pulseless electrical activity, most likely secondary from a hypoxic event caused by aspiration pneumonia. Return of spontaneous circulation occurred in about $2 \mathrm{~min}$ as a result of good cardiopulmonary resuscitation. Speech and swallow services evaluated the patient, but she failed multiple swallow studies. Thus, a decision was made to insert a PEG tube for long-term enteral nutrition.

Interventional radiology was consulted for PEG placement. During the procedure, the stomach was inflated through the existing nasogastric tube. Fluoroscopic evaluation of the abdomen in the anterior projection revealed an air distended colonic loop in front of the stomach (Fig. 1). A lateral view of the stomach confirmed the colonic loop anterior to the stomach, and thus the procedure was aborted given the high risk for colonic injury. The gastrointestinal team then evaluated the patient, and a decision was made to hold clopidogrel for 5 days before attempting PEG placement endoscopically. A preprocedural abdominal X-ray demonstrated paucity of bowel gas in the colon with no colonic loops visualized anterior to the stomach. The patient was then deemed safe for endoscopic PEG placement.

Prior to the procedure, the patient was placed in supine position, and the stomach was insufflated to oppose the gastric and abdominal walls. A site was located in the body of the stomach with excellent transillumination and manual external pressure for placement. The abdominal wall was sterilized, anesthetized and a trocar needle was introduced through the abdominal wall into the stomach under direct endoscopic view. A snare was then introduced through the endoscope in the gastric lumen, and a guide wire passed through the trocar into the open snare. The endoscope and snare were removed, pulling the wire out through the mouth. The PEG tube was inserted through the mouth into the gastric lumen over the guide wire and then pulled out from the stomach through the skin. The position of the PEG tube was confirmed by relook endoscopy, and skin marking was noted to be $8 \mathrm{~cm}$ at the skin and $8.5 \mathrm{~cm}$ at the external bumper. The patient tolerated the procedure extremely well, with no immediate complications.

Post-procedure, a computed tomography of the abdomen was obtained due to pre-procedural concerns for colonic injury. Imaging showed that the gastrostomy tube had traversed the lateral margin of hepatic segment 3 , with an adjacent hematoma measuring $2 \times 2 \times 4 \mathrm{~cm}$ (Fig. 2). On abdominal exam, the PEG tube was freely rotatable; the site was clean and dry, with no blood or drainage. The patient's hemoglobin remained stable after the procedure. Enteral nutrition was started $24 \mathrm{~h}$ after PEG tube insertion, and the patient tolerated tube feeds extremely well, with no complications. The patient was safely discharged to a nursing home for further care. Unfortunately, when contacting the nursing home 1 week later, it was discovered that the patient expired on day 3 of her nursing home stay. The exact etiology of her death remains un-established, as the patient's family denied completion of an autopsy.

\section{Discussion}

Since the introduction of the PEG tube in 1980, it has attained worldwide popularity and is now the modality of choice for long-term enteral nutrition, given its high safety profile and technical ease of insertion via upper gastrointestinal endoscopy. However, as with all procedures, it is also associated with certain complications, and one of the most worrisome risks is injury to adjacent internal organs.

Hepatic injury is an exceptionally rare complication of PEG tube insertion, and we found only six such cases in the medical literature after an extensive PubMed database search [12-16]. Based on the published data, it is apparent that transhepatic PEG insertion can have presentations ranging from asymptomatic, incidental findings to abdominal pain and life-threatening peritonitis or abscess formation. However, it is very possible that the reported cases far underrepresent the 


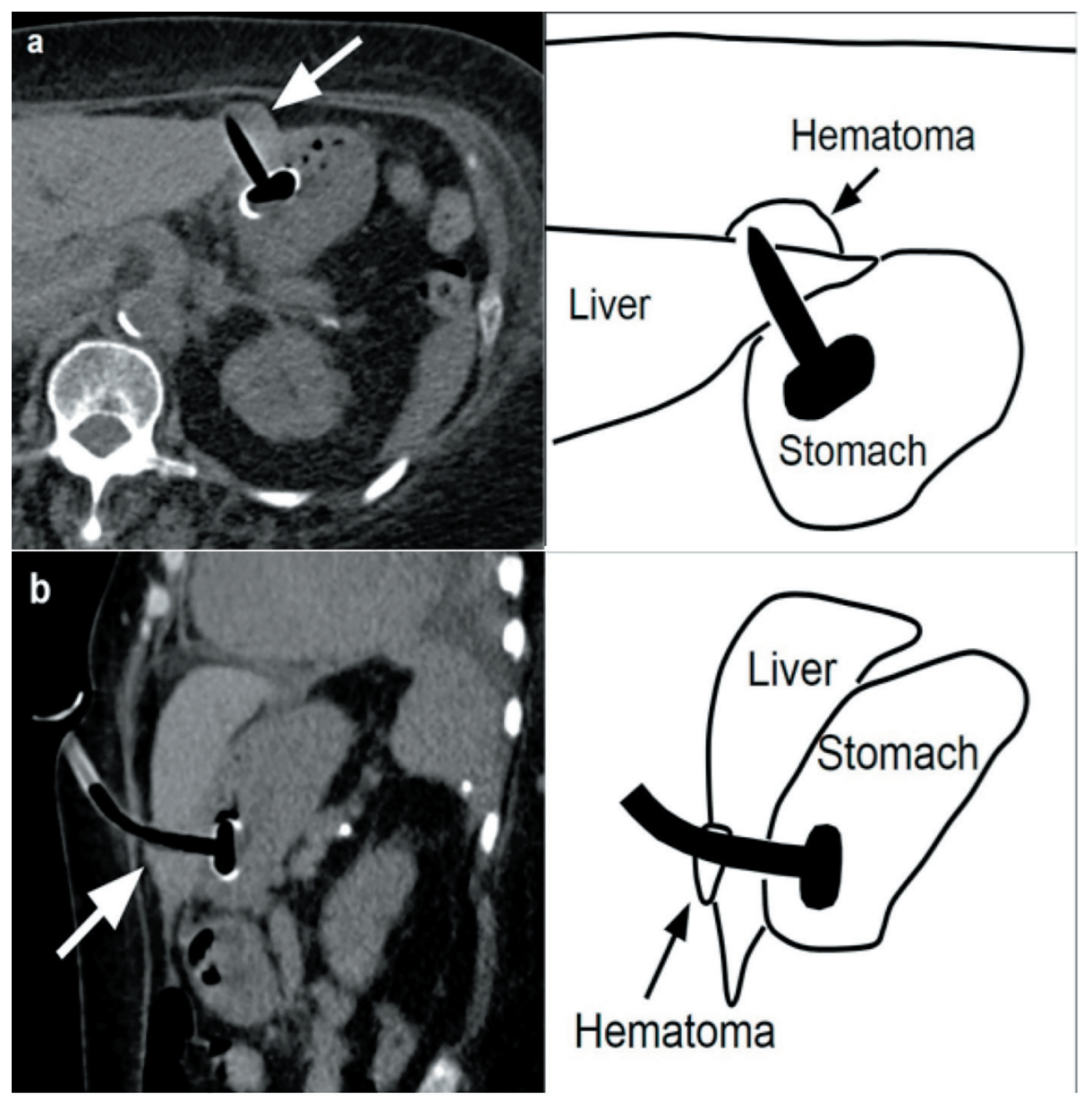

Figure 2. Axial CT (a) showing the percutaneous gastrostomy tube traversing the lateral margin of the liver with adjacent small hematoma (arrow). Accompanying sagittal view (b) and schematics.

actual number of cases, as trans-hepatic PEG insertion may manifest as incidental findings in patients who lack clinical signs or symptoms. Table 1 summarizes the significant aspects of the previously reported cases.

Certain patient-specific factors theoretically can increase the risk of hepatic injury during PEG placement. These include hepatomegaly, trocar insertion at full inspiration, elevated head end of the patient during the procedure, and severe lordosis; all these factors result in caudal displacement of the liver [12]. There are also operator-dependent factors that may be associated with this complication. First, meticulous abdominal exam must be performed prior to the procedure to look for hepatomegaly, and the PEG tube should always be inserted to the left of abdominal midline. If hepatomegaly is appreciated, then a pre-procedural ultrasound must be obtained to further study the anatomical relationship [13]. Second, during the PEG procedure, transillumination and manual external pressure play a key role in identifying a safe site and tract for trocar insertion. This could be jeopardized if there is an interposition of an organ between the stomach and abdominal wall. Third, the "safe tract" technique involves suctioning with a syringe containing $1-2 \mathrm{~mL}$ of saline at the proposed site of trocar insertion. If an air bubble develops in the syringe while the needle is in the gastric lumen (as observed by endoscope) simultaneously, then this indicates a safe zone for PEG insertion. However, if air bubbles are noticed before the needle enters the gastric lumen, then this indicates that the large or small intestine (or another hollow lumen) is in the path of the planned PEG tract [17]. This technique can prove useful in preventing injury to the intestine, but is not effective in detecting hepatic tissue, as it would not form air bubbles. Fourth, it is also debated that an experienced endoscopist may appreciate the "consistency or texture" of hepatic tissue during trocar insertion. However, the bulk of hepatic parenchyma (except the major intrahepatic pedicle) will not provide a different feel during the insertion of a sharp trocar [12]. Fifth, the "air insufflation technique" involves insufflating the empty stomach with about $500 \mathrm{~mL}$ of air via nasogastric tube and observing the anatomical relationship of the stomach with the liver and intestine on plain abdominal radiograph. This could facilitate localization of the best site of trocar insertion in order to minimize damage to neighboring organs [18].

Diagnosis of asymptomatic patients with accidental transhepatic PEG placement needs a high index of suspicion and can be very challenging. Unexplained elevation of liver transaminase after the procedure could be the only marker of this event 
Table 1. Significant Aspects of the Previously Reported Cases

\begin{tabular}{|c|c|c|c|c|c|c|c|}
\hline Author & Age/sex & Indication & PEG technique & Presentation & Diagnosis & Treatment & Outcome \\
\hline $\begin{array}{l}\text { Chaer et al } \\
(2003)[12]\end{array}$ & $\begin{array}{l}78 \text { years/ } \\
\text { female }\end{array}$ & $\begin{array}{l}\text { Oropharyngeal } \\
\text { cancer }\end{array}$ & $\begin{array}{l}\text { Trans } \\
\text { illumination } \\
\text { (pull technique) }\end{array}$ & $\begin{array}{l}2.5 \text { months } \\
\text { later with } \\
\text { concerns } \\
\text { for tube } \\
\text { malfunction }\end{array}$ & $\begin{array}{l}\text { Contrast } \\
\text { radiograph: PEG } \\
\text { tube within liver }\end{array}$ & $\begin{array}{l}\text { Laparotomy: } \\
\text { removal of } \\
\text { PEG tube and } \\
\text { placement of } \\
\text { new tube }\end{array}$ & $\begin{array}{l}\text { No long term } \\
\text { complication }\end{array}$ \\
\hline $\begin{array}{l}\text { Gubler et al } \\
(2005)[13]\end{array}$ & $\begin{array}{l}59 \text { years/ } \\
\text { male }\end{array}$ & $\begin{array}{l}\text { Nasopharyngeal } \\
\text { cancer }\end{array}$ & $\begin{array}{l}\text { Trans } \\
\text { illumination }\end{array}$ & $\begin{array}{l}1 \text { week } \\
\text { later with } \\
\text { pain around } \\
\text { PEG site }\end{array}$ & $\begin{array}{l}\text { Ultrasound: } \\
\text { PEG tube along } \\
\text { edge of left } \\
\text { liver lobe }\end{array}$ & $\begin{array}{l}\text { 10-day course of } \\
\text { analgesics with } \\
\text { pain resolution }\end{array}$ & $\begin{array}{l}\text { Asymptomatic at } 6 \\
\text { month follow up }\end{array}$ \\
\hline $\begin{array}{l}\text { Gubler et al } \\
(2005)[13]\end{array}$ & $\begin{array}{l}81 \text { years/ } \\
\text { female }\end{array}$ & $\begin{array}{l}\text { Esophageal } \\
\text { cancer }\end{array}$ & $\begin{array}{l}\text { Trans } \\
\text { illumination }\end{array}$ & $\begin{array}{l}1 \text { week } \\
\text { later with } \\
\text { abdominal } \\
\text { discomfort }\end{array}$ & $\begin{array}{l}\text { Ultrasound: } \\
\text { PEG tube along } \\
\text { edge of left } \\
\text { liver lobe }\end{array}$ & $\begin{array}{l}3 \text {-week course of } \\
\text { analgesics with } \\
\text { pain resolution }\end{array}$ & $\begin{array}{l}\text { Death at } 6 \text { weeks } \\
\text { from respiratory } \\
\text { failure, unrelated to } \\
\text { PEG }\end{array}$ \\
\hline $\begin{array}{l}\text { Burke et al } \\
(2009)[15]\end{array}$ & $\begin{array}{l}33 \text { years/ } \\
\text { male }\end{array}$ & $\begin{array}{l}\text { Intracranial } \\
\text { hemorrhage }\end{array}$ & $\begin{array}{l}\text { Trans } \\
\text { illumination }\end{array}$ & $\begin{array}{l}\text { Fevers, } \\
\text { chills and } \\
\text { transaminitis } \\
\text { after } 7 \text { weeks } \\
\text { of placement }\end{array}$ & $\begin{array}{l}\text { Computed } \\
\text { Tomography: } \\
\text { PEG tube } \\
\text { terminus } \\
\text { outside stomach } \\
\text { near liver }\end{array}$ & $\begin{array}{l}\text { Antibiotics, } \\
\text { Laparotomy: } \\
\text { tube removal and } \\
\text { closure of gastro- } \\
\text { hepatic fistula. }\end{array}$ & $\begin{array}{l}\text { Abscess } \\
\text { development a week } \\
\text { after laparotomy, } \\
\text { drained under } \\
\text { sonographic } \\
\text { guidance. Long term } \\
\text { outcome not } \\
\text { mentioned }\end{array}$ \\
\hline
\end{tabular}

[15]. A mild drop in hemoglobin can also be present if there is a development of concomitant hematoma. However, many patients undergoing PEG procedure are very sick to begin with, and minor fluctuations in the aforementioned labs could easily be ignored. Progressive pain around the PEG site or pain with tube feeding could be a significant clinical indicator, but this history is not always available in certain patients, for example those undergoing PEG for advanced dementia, with aphasia from stroke and post-tracheostomy, among others. If there is a clinical concern, diagnosis should be established with abdominal ultrasound using high-resolution linear array transducer. This technique can detect injury to liver parenchyma even at the margins, which may not be visible on computed tomography [16].

The patient described in this case report was morbidly obese (BMI $34 \mathrm{~kg} / \mathrm{m}^{2}$ ), and a thick layer of abdominal fat made it difficult to palpate the liver and delineate its margins (the liver was of normal size on computed tomography done after the procedure). Abdominal obesity could also hamper the quality of transillumination and external pressure, increasing the susceptibility of adjacent organs to injury (excellent transillumination and external pressure was achieved during the procedure in our case). Our patient had a stroke resulting in aphasia and could not communicate any abdominal symptoms she might have been having. Liver transaminases were not obtained prior to or after the PEG placement; no changes in hemoglobin were noted on her labs, despite the presence of a small hematoma around the PEG site. Unfortunately, she died within 1 week after PEG placement from an unidentified etiology, as an autopsy was not done. Her death may or may not have been related to the PEG placement, as overall mortality in patients receiving PEG is especially high in the presence of multiple comorbidities. In patients receiving PEG, 2-month mortality could be as high as 18\% [19], and 1-month mortality up to $10 \%$, from causes unrelated to PEG placement [20]. In addition, patients undergoing PEG for neurological issues are at significantly higher risk than patients getting it for other indications. 
In conclusion, trans-hepatic insertion of a PEG tube is an extremely rare but dreaded complication of the PEG procedure, with only a handful of cases described in the literature. No standard treatment guidelines have been described for management of these patients. However, based on the limited data available, it should be reasonable to leave the tube in place if patients are asymptomatic and tolerating tube feeds. In patients who are symptomatic, it might be prudent to replace the tube [16]. In the future, more data are needed to assist with the formulation of management strategies.

\section{Author Contributions}

Chhaparia A and Hammami MB equally contributed to this paper with conception, literature review, analysis and drafting. Bassuner $\mathrm{J}$ contributed to this paper by providing high quality radiology images. Hachem $\mathrm{C}$ contributed to this paper with critical revision and editing, and approval of the final version.

\section{Supportive Foundations}

None.

\section{Conflict of Interest}

None.

\section{Financial Support}

None.

\section{References}

1. Gauderer MW, Ponsky JL, Izant RJ, Jr. Gastrostomy without laparotomy: a percutaneous endoscopic technique. J Pediatr Surg. 1980;15(6):872-875.

2. Mendiratta P, Tilford JM, Prodhan P, Curseen K, Azhar G, Wei JY. Trends in percutaneous endoscopic gastrostomy placement in the elderly from 1993 to 2003. Am J Alzheimers Dis Other Demen. 2012;27(8):609-613.

3. Wilhelm SM, Ortega KA, Stellato TA. Guidelines for identification and management of outpatient percutaneous endoscopic gastrostomy tube placement. Am J Surg. 2010;199(3):396-399; discussion 399-400.

4. Heidegger CP, Darmon P, Pichard C. Enteral vs. parenteral nutrition for the critically ill patient: a combined support should be preferred. Curr Opin Crit Care. 2008;14(4):408-414.

5. Itkin M, DeLegge MH, Fang JC, McClave SA, Kundu S, d'Othee BJ, Martinez-Salazar GM, et al. Multidisciplinary practical guidelines for gastrointestinal access for enteral nutrition and decompression from the Society of Interventional Radiology and American Gastroentero- logical Association (AGA) Institute, with endorsement by Canadian Interventional Radiological Association (CIRA) and Cardiovascular and Interventional Radiological Society of Europe (CIRSE). Gastroenterology. 2011;141(2):742-765.

6. Jaafar MH, Mahadeva S, Morgan K, Tan MP. Systematic review of qualitative and quantitative studies on the attitudes and barriers to percutaneous endoscopic gastrostomy feeding. Clin Nutr. 2016;35(6):1226-1235.

7. Hucl T, Spicak J. Complications of percutaneous endoscopic gastrostomy. Best Pract Res Clin Gastroenterol. 2016;30(5):769-781.

8. Karhadkar AS, Schwartz HJ, Dutta SK. Jejunocutaneous fistula manifesting as chronic diarrhea after PEG tube replacement. J Clin Gastroenterol. 2006;40(6):560-561.

9. Guloglu R, Taviloglu K, Alimoglu O. Colon injury following percutaneous endoscopic gastrostomy tube insertion. J Laparoendosc Adv Surg Tech A. 2003;13(1):6972.

10. Ahmad J, Thomson S, McFall B, Scoffield J, Taylor M. Colonic injury following percutaneous endoscopic-guided gastrostomy insertion. BMJ Case Rep. 2010;2010.

11. Roos J. A case of small-bowel obstruction after insertion of a percutaneous endoscopic gastrostomy tube due to mesenteric penetration. Ann R Coll Surg Engl. 2015;97(5):e79-80.

12. Chaer RA, Rekkas D, Trevino J, Brown R, Espat J. Intrahepatic placement of a PEG tube. Gastrointest Endosc. 2003;57(6):763-765.

13. Gubler C, Wildi SM, Bauerfeind P. Liver injury during PEG tube placement: report of two cases. Gastrointest Endosc. 2005;61(2):346-348.

14. Wiggins TF, Kaplan R, DeLegge MH. Acute hemorrhage following transhepatic PEG tube placement. Dig Dis Sci. 2007;52(1):167-169.

15. Burke DT, Geller AI. Peritonitis secondary to the migration of a trans-hepatically-placed percutaneous endoscopic gastrostomy tube: a case report. Arch Phys Med Rehabil. 2009;90(2):354-357.

16. Herta T, Hecker M, van Boemmel F, Hoffmeister A, Karlas T. Sonographic diagnosis of transhepatic placement of a percutaneous endoscopic gastrostomy (PEG) tube. Endoscopy. 2015;47(Suppl 1 UCTN):E453-454.

17. Foutch PG, Talbert GA, Waring JP, Sanowski RA. Percutaneous endoscopic gastrostomy in patients with prior abdominal surgery: virtues of the safe tract. Am J Gastroenterol. 1988;83(2):147-150.

18. Chang WK, Hsieh TY. Safety of percutaneous endoscopic gastrostomy in high-risk patients. J Gastroenterol Hepatol. 2013;28(Suppl 4):118-122.

19. Blomberg J, Lagergren J, Martin L, Mattsson F, Lagergren P. Complications after percutaneous endoscopic gastrostomy in a prospective study. Scand J Gastroenterol. 2012;47(6):737-742.

20. Schneider AS, Schettler A, Markowski A, Luettig B, Kaufmann B, Klamt S, Lenzen H, et al. Complication and mortality rate after percutaneous endoscopic gastrostomy are low and indication-dependent. Scand J Gastroenterol. 2014;49(7):891-898. 